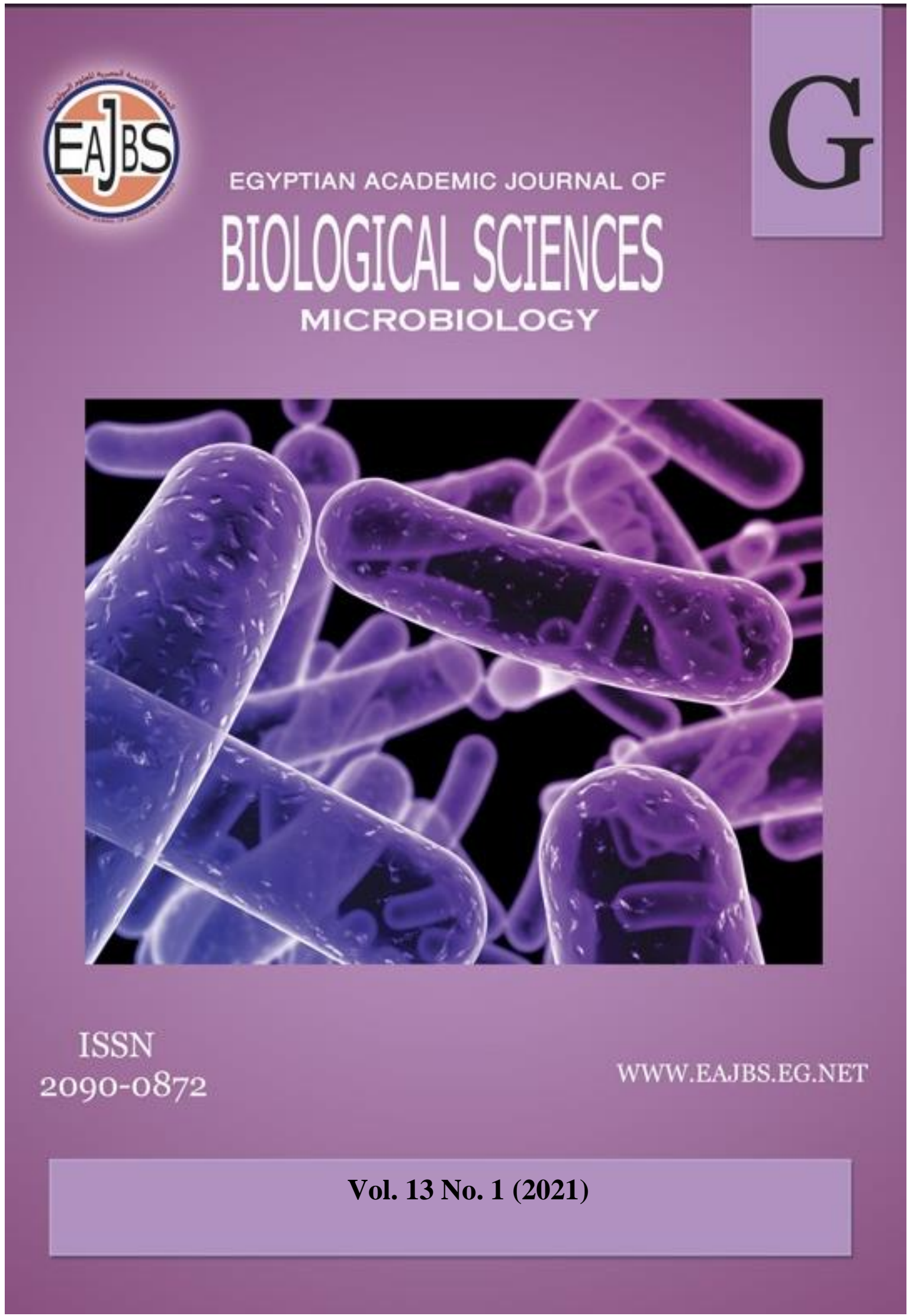

Citation: Egypt. Acad. J. Biolog. Sci. (G.Microbiolog) Vol.13 (1) pp.29- 47 (2021) DOI: 10.21608/EAJBSG.2021.172883 
Egypt. Acad. J. Biolog. Sci., 13(1):29-47(2021)

\begin{tabular}{c}
$\begin{array}{c}\text { Egyptian Academic Journal of Biological Sciences } \\
\text { G. Microbiology } \\
\text { ISSN: 2090-0872 } \\
\text { https://eajbsg.journals.ekb.eg/ }\end{array}$ \\
\hline
\end{tabular}

\title{
Rational of Invertebrates and Herbs Extracts for Protection and Management of Coronavirus (COVID 19)
}

\author{
Fatma El-Zahraa A. Abd El-Aziz ${ }^{1 *}$, Soheir Mustafa Kasem ${ }^{2}$, Marwa F.Ali ${ }^{3}$, Shereen M. \\ Mohamed $^{4}$, and Doaa M. El Shehaby ${ }^{5}$
}

1-Department of Zoology, Faculty of Science, Assiut University, Assiut, 71526, Egypt.

2-Department of Internal Medicine and Critical care, Faculty of Medicine, Assiut University.

3-Department of Veterinary Pathology and Clinical Pathology, Faculty of Veterinary Medicine, Assiut University.

4-Department of Medical Microbiology and Immunology, Faculty of Medicine, Assiut University.

5-Department of Forensic Medicine \& Clinical Toxicology, Faculty of Medicine, Assiut University.

E-mail: F_Abdelhameed@yahoo.com - fatma.abdelgalil1@ science.aun.edu.eg

ORCID: iD: https://orcid.org/0000-0001-7260-7598

\section{REVIEW INFO}

\section{ReviewHistory}

Received: 25/3/2021

Accepted:12/5//2021

Available: $13 / 5 / 2021$

Keywords:

Coronavirus

(COVID-19),

Pathogenesis,

invertebrates and

herbs extracts.

\section{ABSTRACT}

A novel outbreak of coronavirus [severe acute respiratory syndromecoronavirus 2 (SARS-CoV-2)] has caused a global coronavirus disease pandemic in 2019 (COVID-19), leading to tens of thousands of infections and thousands of deaths worldwide. Coronaviruses are implicated in illnesses of humans, vertebrates and invertebrates. There is currently no effective treatment for COVID-19. Due to the high rate of transmission between humans of this virus and its pandemics, it is necessary to determine the fundamentals of its replication, structure and pathogenicity for finding a way to special treatment or prevention. COVID-19 virus pathogenesis has not been fully grasped. The key point of the pathogenic effect of COVID-19virus is its effect on angiotensin-converting enzyme2 (ACE2) receptors that play a major role in virus entry into the cell causing ending lesions. ACE2 receptors present in many human cell types in many organs such as lungs, arteries, heart, kidneys, intestines, nervous system and skeletal muscles. From ancient times, antiviral agents extracted from natural herbal and invertebrate sources have been used to prevent and treat a number of viral infections including respiratory viral infections. COVID-19 management is believed to be based on two strategies; enhancement of the immunity to control viral replication or virulence and relieve associated symptoms. This review strengthens the use of natural extracts as valuable tools to develop new therapeutic drugs against COVID-19 (Fig.1). 


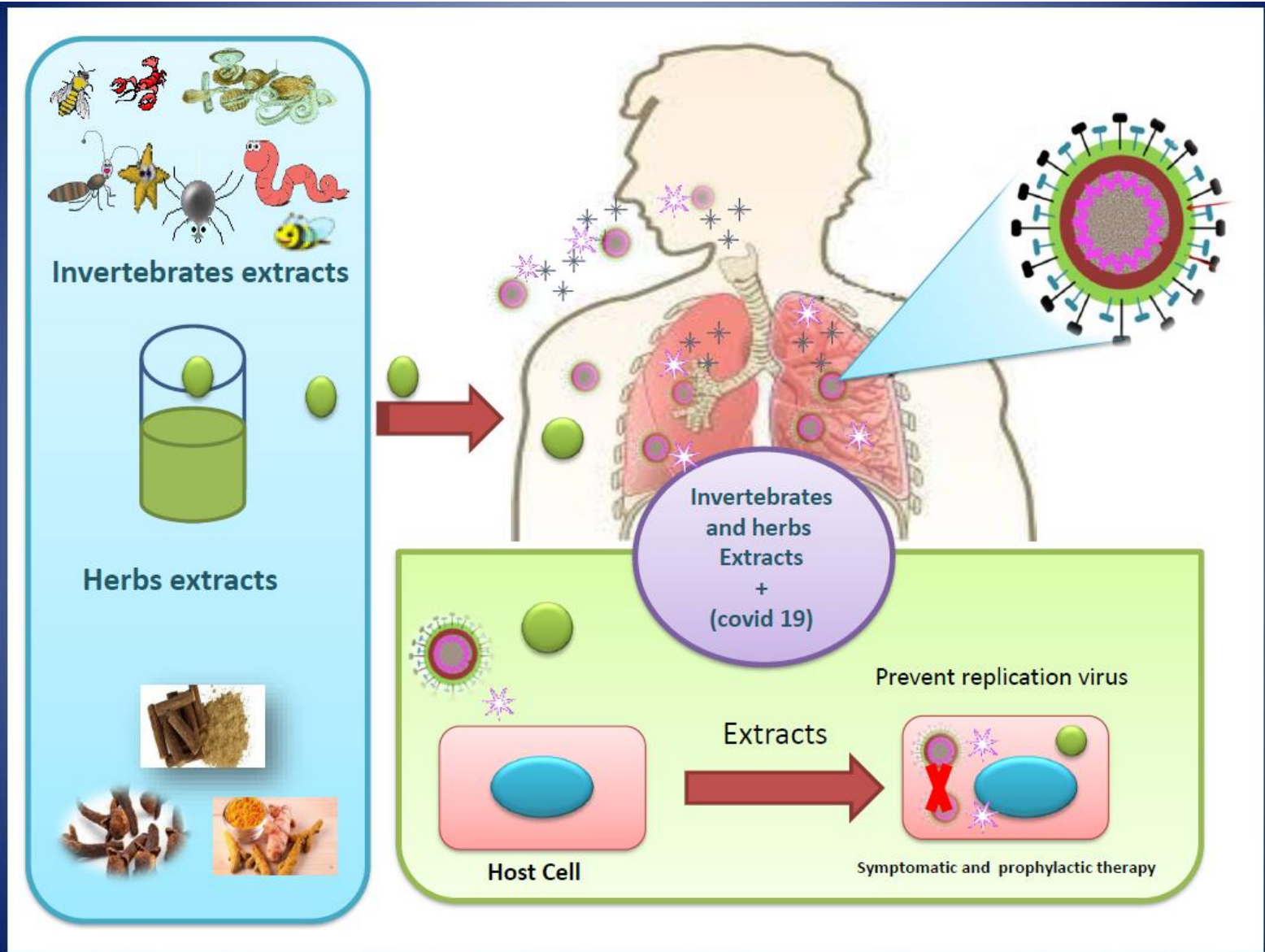

Fig.1. Invertebrates and Herbs Extracts for Protection and Management of Coronavirus (COVID 19).

\section{ABBREVIATIONS}

(TCM): Traditional Chinese Medicine, (HE): hemagglutinin-esterase, angiotensin-converting enzyme2,(CNS): central nervous system, (BALF): bronchoalveolar lavage fluid, (MNPs): marine natural products.

\section{INTRODUCTION \\ 1.Coronavirus (COVID-19):}

This is a recent pandemic defined as an infectious disease caused by extreme acute respiratory coronavirus syndrome 2 (SARSCoV-2) (Hui et al, 2020). In early January 2020, two coronavirus RNA were identified as the cause of a pneumonia epidemic affecting the city of Wuhan, from where it rapidly spread across China. One is Severe Acute Respiratory Syndrome Coronavirus (SARS-CoV-2), a novel RNA coronavirus that belongs to the same family of SARS-CoV and the other is the Middle East Respiratory Syndrome Coronavirus (MERS-CoV). After infecting and causing thousands of deaths in China, the non-stop viral infection reached Italy and other European countries (Remuzzi\&Remuzzi, 2020, Holshue, et $a l ., 2020$ and Bernard, et al,2020). In the USA with the number of confirmed new cases are currently increasing every day.

Due to the high contagion rate and widespread infectivity, World Health Organization (WHO) declared the disease a pandemic under the name coronavirus disease 2019 (COVID-19) (Liu et al., 2020). Human coronaviruses tend to cause enteric and pulmonary infections (Liu et al., 2020). The new coronavirus has become a global health concern (Mahase,2020): until 23 $3^{\text {rd }}$ October 2020, COVID-19 has caused $1,132,879$ deaths worldwide and infected more than 41,332,899 people (WHO, 2020). Egypt's Ministry of Health announced on 31 March that it had recorded 54 new positive COVID-19 infections and 5 new deaths. On 
30 April, the Ministry of Health had recorded 269 new cases, positive COVID-19 infections and 12 new deaths. On $16^{\text {th }}$ June, the Ministry of Health had recorded 47,856 total cases and 1,766 total deaths. From the beginning of the corona outbreak till $23^{\text {rd }}$ October, the Ministry of health in Egypt announced that total infected cases reached 106,060 and 6,166 deaths. EL-Mahdi (2020) studied the Coronavirus sequence analysis and variations in the 5' UTR genomic regions. Dalia et al., (2021) mentioned that Despite substantial advances made by scientists based on numerous experiments and clinical trials, no definitive cure exists at this time. However, the possibility of a preventive or therapeutic vaccine appears to be growing.

\section{Taxonomy:}

Coronaviruses (CoVs) belong to the order of Nidovirales, which involves families of Coronaviridae, Arteriviridae, Mesoniviridae, and Roniviridae. Coronavirinae is further subdivided into four genera, the coronaviruses alpha, beta, gamma and delta. Originally, the viruses were classified into these genera based on serology but are now categorized by phylogenetic clusters (Helena et al., 2015) (Fig.2).

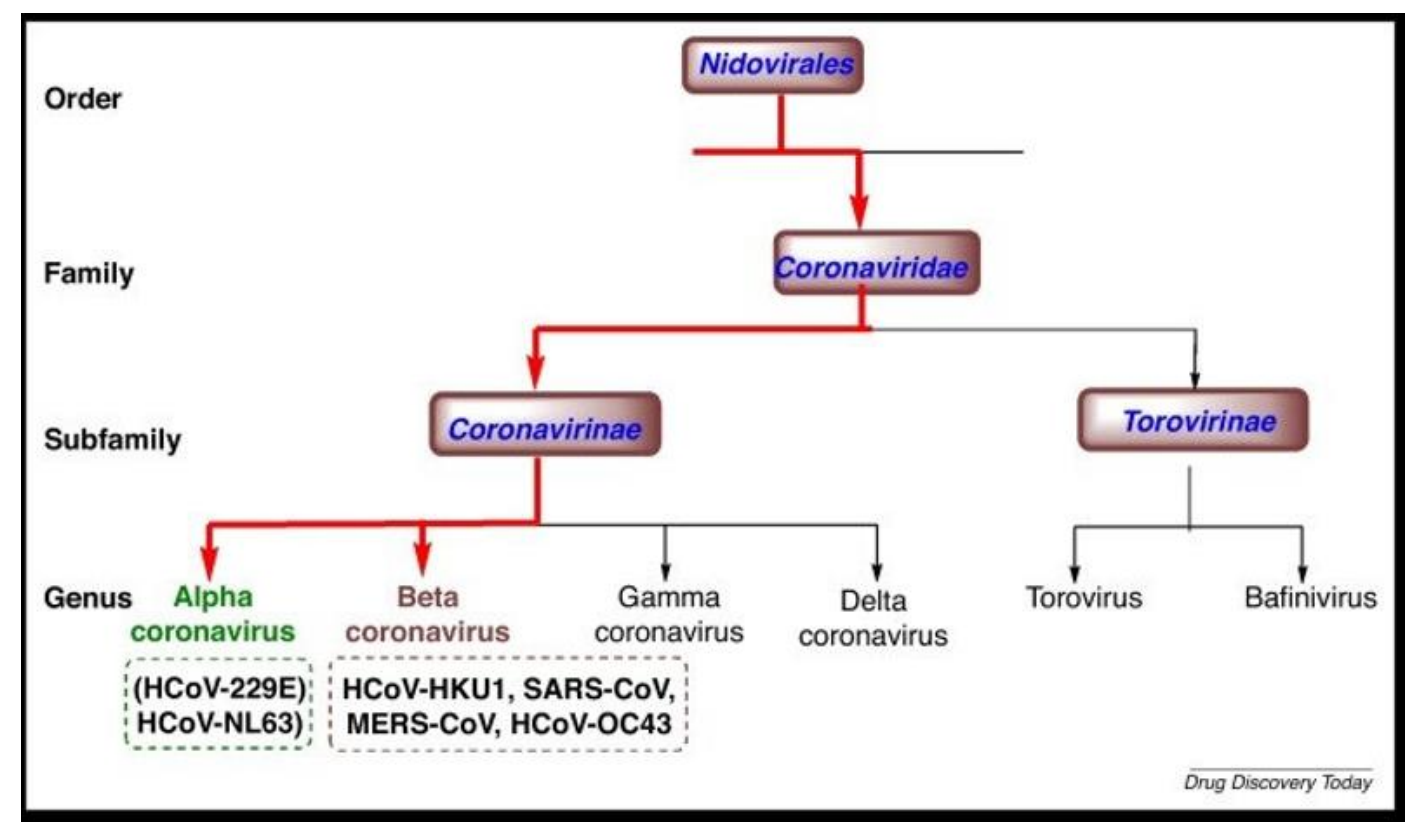

Fig.2. Taxonomy of coronaviruses (Source: www.sciencedirect.com).

The seven coronaviruses which can get humans infected humans are:

- Alpha coronaviruses; 229E and NL63.

- Beta coronavirus; OC43, HKU1, MERSCoV (known to cause Middle East Respiratory Syndrome or MERS), SARS$\mathrm{CoV}$ (known to cause severe Acute Respiratory Syndrome or SARS) and SARS-CoV-2 (the novel coronavirus that causes coronavirus disease 2019, or COVID-19) (CDC, 2020).

\section{Clinical Manifestations:}

COVID-19 is primarily a disease with respiratory manifestations, there are increasing reports of cardiovascular and thrombotic complications which are important for clinicians to be aware of. It is known that during infection with COVID-19, there is a pro-inflammatory immune response with high levels of inflammatory processes are associated with a hypercoagulable state (Hughes, et al.,2020). Coronavirus SARSCoV-2 was identified as the cause of an outbreak of severe pneumonia known as covid-19(Zhou, et al. 2020). The spread of covid-19 has increased exponentially, with the WHO declaring a pandemic on $11^{\text {th }}$ March 
(WHO, 2020). Severe acute respiratory illness with fever and respiratory symptoms, such as cough and shortness of breath, comprise the working case definition used to select people for viral testing. This strategy captures typical symptomatic presentation, but imperfectly identifies unusual manifestations, such as patients without respiratory symptoms or only very mild symptoms (Vetter, et al,2020).

The majority of patients with COVID19 present common symptoms that include fever, shortness of breath, cough (either with or without sputum), sore throat, nasal congestion, dizziness, chills, muscle ache, arthralgia, weakness, fatigue or myalgia, chest tightness, excessive mucus production with expectoration, hemoptysis, and dyspnea (Lei, et al, 2020). Even though fever is not the only initial clinical manifestation of SARSCoV-2 infection, it is considered to be critical (Huang, et al.,2020).

Other less characteristic symptoms include headache, diarrhea, abdominal pain, vomiting, chest pain, rhinorrhoea, or pharyngalgia (Wu, et al.,2020).

3.1. The Clinical Manifestations of The Disease Can Be Classified by Their Severity Into) (Wu and McGoogan ,2020):

- Mild Disease: non-pneumonia and mild pneumonia; this occurred in $81 \%$ of cases.

- Severe Disease: dyspnea, respiratory frequency $\geq 30 / \mathrm{min}$, blood oxygen saturation $\left(\mathrm{SpO}_{2}\right) \leq 93 \%, \mathrm{PaO}_{2} / \mathrm{FiO}_{2}$ ratio or $\mathrm{P} / \mathrm{F}$ [the ratio between the blood pressure of the oxygen (partial pressure of oxygen, $\mathrm{PaO}_{2}$ ) and the percentage of oxygen supplied (fraction of inspired oxygen, $\mathrm{FiO}_{2}$ ) $<300$, and/or lung infiltrates $>50 \%$ within 24 to 48 hours; this occurred in $14 \%$ of cases.

- Critical Disease: respiratory failure, septic shock, and/or multiple organ dysfunction (MOD) or failure (MOF); this occurred in $5 \%$ of cases.

Among 81 fatal cases of patients from Wuhan, the most common cause of death was respiratory failure (46.91\%), followed by septic shock (19.75\%), multiple organ failure $(16.05 \%)$, and cardiac arrest $(8.64 \%)$. Rarer death causes were acute coronary syndrome, malignant arrhythmia, or disseminated intravascular coagulation (DIC) (Du, et al.,2020).

\subsection{Non-Respiratory Manifestations of Covid19:}

- Neurological Symptoms, including headache, languidness, malaise, cerebral hemorrhage, or cerebral infarction (Yin, et al.,2019). Cases of encephalitis, necrotizing hemorrhagic encephalopathy, strokes, epileptic seizures, or rhabdomyolysis associated with SARSCoV-2 infection have also been described (Carod-Artal, 2020).

- Olfactory and Gustatory Dysfunctions, anosmia might constitute the only symptom of COVID-19 (Hopkins, et $a l ., 2020)$. The mean duration of smell and taste disorders due to SARS-Cov-2 is estimated at 7.5 days (BeltránCorbellini,2020).

- Gastrointestinal and Hepatic Manifestations, a significant number of studies indicate that SARS-CoV-2 actively infects and replicates within the gastrointestinal tract, inducing digestive symptoms primarily via overexpression of viral receptor angiotensin-converting enzyme 2 (ACE2), found in gastrointestinal epithelial cells (Xiao, et al.,2020). Infection might involve liver impairments of a wide spectrum of a severity degree. COVID-19 patients show increased levels of ALT and AST. Furthermore, serum bilirubin and gammaglutamyl transferase (GGT) might also be elevated during the disease (Bloom, et al.,2020).

\section{- Ophthalmic}

Manifestations, coronaviruses can induce a wide spectrum of ophthalmic manifestations, such as conjunctivitis, anterior uveitis, retinitis, or optic neuritis (Seah, and Agarwal, 2020).

- Cardiovascular Manifestations, cardiac impairments might occur even without any symptoms or signs of pneumonia. The pathophysiological mechanisms probably involve ACE2 receptors, a cytokine storm induced by the imbalanced response between type 1 and 2 T-helper cells or 
strong

immunopathological

interferon-mediated al.,2020). The most prevalent cardiovascular complication of COVID-19 is an acute myocardial injury (usually defined as an increase in cardiac troponin I above the $99^{\text {th }}$ percentile upper reference limit), with a prevalence of $8 \%-12 \%$ (Kang, et al.,2020).

Furthermore, acute pulmonary embolism and aortic thrombosis might be non-characteristic presentations in COVID19 patients (Grillet, et al.,2020). Like other viral types of pneumonia, patients infected by SARS-CoV-2 are at a higher risk of an acute pulmonary embolism. COVID-19 patients with pulmonary embolus have higher $\mathrm{D}$ dimer levels compared to infected patients without pulmonary embolism (Griffin, et al., 2020). Fortunately, nature provides us with an extensive chemical library to explore and produce medicines for the prevention and/or treatment of various pathogens, including viral diseases (Griffin, et al,. 2020). So far, a significant number of natural extracts either from animal sources such as invertebrates or herbal medicines, have revealed feasible antiviral effects (Kang, et al.,2020). Nonetheless, there is not enough work on the production of anti-CoV remedies from such natural products. These agents are important not only for fighting $\mathrm{CoV}$, but also for avoiding viral attacks. Based on the previous discussion, the intent of this analysis is to provide an overview of the current status of natural compounds and/or their derivatives from animal or plant origins working against various $\mathrm{CoV}$ species.

\section{Coronavirus Structure and Genome Organization:}

COVID-19 is a single-stranded (positive-sense) RNA spherical or pleomorphic enveloped particle associated with a nucleoprotein inside a matrix protein capsid. The envelope bears glycoprotein projections in club-shaped form. Some coronaviruses also contain a protein called hemagglutinin-esterase (HE) (Fig.3).

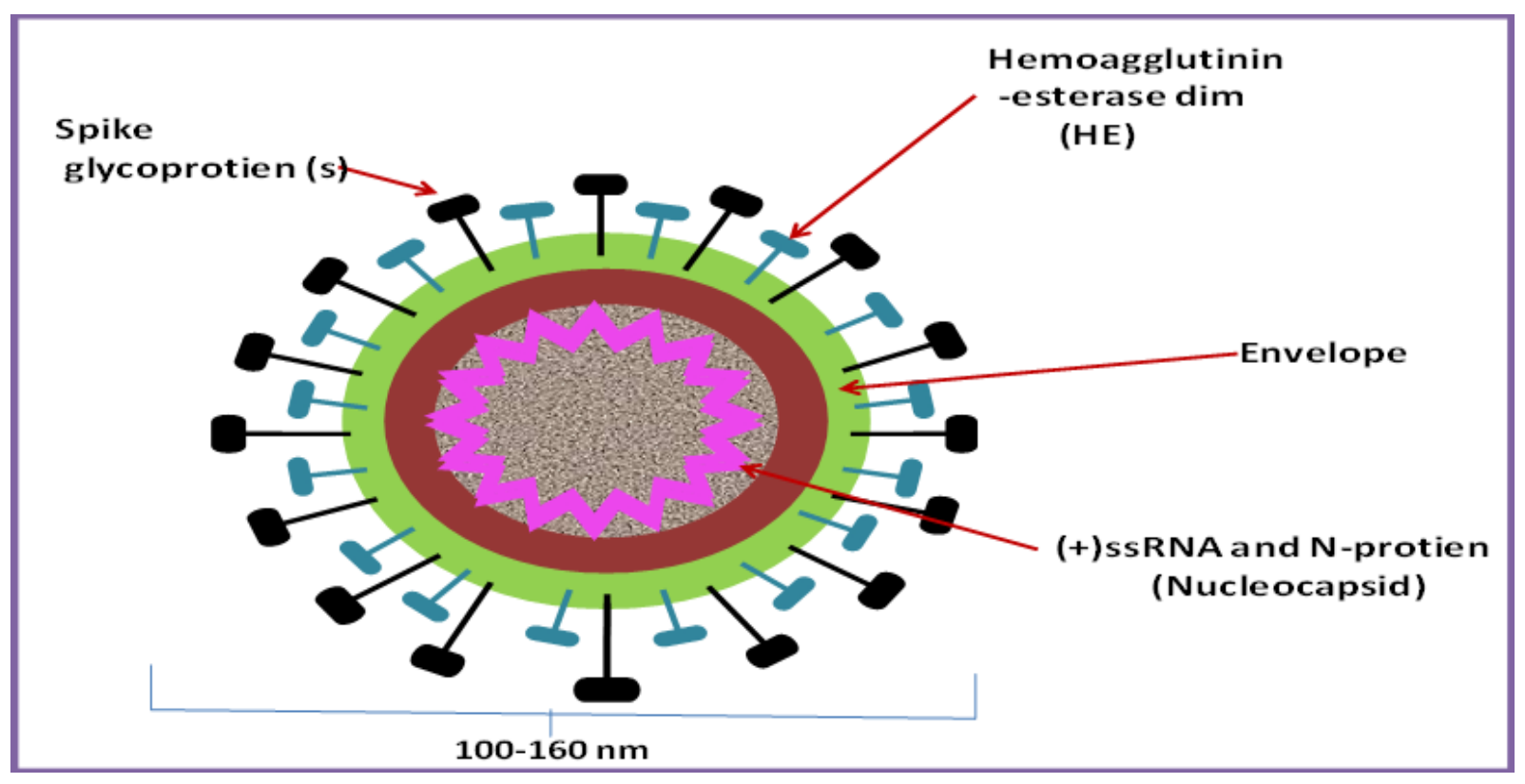

Fig. 3: Schematic of a Coronavirus (COVID-19) structure.

Coronaviruses possess about $30 \mathrm{~kb}$ of then on-segmented, positive-sense RNA genome. The genome comprises a $5^{\prime}$ cap structure and a $3^{\prime} \operatorname{poly}(\mathrm{A})$ tail, enabling it to serve as mRNA for polyprotein replicase translation. The replicase gene encoding the non-structural proteins (nsps 1-16) constitutes two-thirds (approximately $20 \mathrm{~kb}$ ) of the genome. A leader sequence and untranslated region (UTR)with several stem-loop 
structures present at the $5^{\prime}$ end of the genome is believed to be essential for replication and transcription of the viral RNA. Additionally, transcriptional regulatory sequences (TRSs) found at the beginning of each structural or accessory gene are needed for the expression of each of these genes. The 3' UTR also contains RNA structures essential for viral RNA replication and synthesis (Zhao, et al., 2012).

The organization of the coronavirus genome is $5^{\prime}$-leader-UTR-replicase-S (Spike)-E (Envelope)-M (Membrane)-N (Nucleocapsid)-3' UTR-poly (A) tail with accessory genes interspersed within the structural genes at the $3^{\prime}$ end of the genome. The accessory proteins are almost exclusively nonessential for replication in tissue culture; however, some have been shown to have important roles in viral pathogenesis (Zhao, et al., 2012).

Coronaviruses $(\mathrm{CoV}) \quad$ are characterized by; being pleomorphic particles, size from 80 to $120 \mathrm{~nm}$, their replication cycle entirely occurs in the cytoplasm (Van Regenmortel, et al.,2020). The $\mathrm{CoV}$ envelope is involved in critical aspects of the viral life cycle (Punithavathi, et al.,2003). Coronavirus could possibly infect animals as well as humans causing severe respiratory complications and gastroenteritis, in addition to hepatitis, systemic diseases, and even death in birds, humans, and other animals (Pradesh, et al.,2014). Moreover, CoVs were found to be the causative agents of Middle East Respiratory Syndrome (MERS$\mathrm{CoV})$ and Severe Acute Respiratory Syndrome (SARS-CoV-2). A novel coronavirus 2019 (nCoV-19) has been newly identified in humans that caused thousands of deaths from January to March 2020 (Hui et al, 2020).

Most of the nsps have been reported for their specific roles in the replication of CoVs. However, the functions of some of the nsps are unknown or not well understood. Four structural proteins are essential for virion assembly and infection of CoVs. Homotrimers of $\mathrm{S}$ proteins make up the spikes on the viral surface and they are responsible for attachment to host receptors. The $\mathrm{M}$ protein has three transmembrane domains and it shapes the virions, promotes membrane curvature, and binds to the nucleocapsid. The E protein plays a role in virus assembly and release, and it is involved in viral pathogenesis. The $\mathrm{N}$ protein contains two domains, both of which can bind the virus RNA genome via different mechanisms. It is reported that $\mathrm{N}$ protein can bind to nsp3 protein to help tether the genome to RTC and package the encapsidated genome into virions. $\mathrm{N}$ protein is also an antagonist of interferon (IFN) and virally encoded repressor of RNA interference, which appears to be beneficial for viral replication (Chen $\mathrm{Yu}$, et al.,2020).

\section{Modes of Transmission of TheCOVID- 19 Virus:}

Droplet transmission occurs when a person is inclose contact (within $1 \mathrm{~m}$ ) with someone who has respiratory symptoms (e.g., coughing or sneezing) and is, therefore, his/her mucosae (mouth and nose) or conjunctiva (eyes) exposed to potentially infective respiratory droplets (Who,2020). When the droplet particles are $>5-10 \mu \mathrm{m}$ in diameter they are referred to as respiratory droplets, and when $<5 \mu \mathrm{m}$ in diameter, they are referred to as droplet nuclei (Who,2014). Transmission may also occur through fomites in the immediate environment around the infected person (Ong, et al.,2020).

Airborne transmission (the presence of microbes within droplet nuclei which can remain in the air for long periods of time and be transmitted to others over distances greater than $1 \mathrm{~m}$ ) may be possible in specific circumstances and settings in which procedures or support treatments that generate aerosols are performed; i.e. endotracheal intubation, bronchoscopy, open suctioning... etc. (Liu, et al.,2020). Several case studies have reported gastrointestinal symptoms and/or evidence that some patients with SARS-CoV-2 infection have viral RNA or live infectious virus present in faeces, which suggests that another possible route might be faecal-oral transmission (Xu, et al., 2020). 


\section{Pathogenesis:}

The pathogenesis of the Covid19virus isnot wholly understood. The key point of the pathogenic effect of the Covid-19 virus is its effect on angiotensin-converting enzyme2 (ACE2) receptors which play a main role in the entry of the virus into the cell to cause the ending lesions. ACE2 is attached in many types of cells in many organs such as lungs, arteries, heart, kidney, intestines, nervous system and skeletal muscle.

\section{Effect of Covid-19 on Respiratory:}

Inhalation or touching the nasal mucous membrane is the main route of virus entry to the respiratory tract. The virus is directing the ACE2receptors (Letko, et al.,2020), which present on type II pneumocytes. lung alveoli produce normally surfactant which stimulates increasing pulmonary compliance, prevent atelectasis at the end of expiration and convert collapsed alveoli and open them. reducing surfactant level which occurred when Covid-19 infects type II pneumocytes causing their destruction during the budding out process. Macrophages secrete different types of cytokines such as interleukin $1 \beta$, interleukin 6 , interleukin -8 interleukin -10 and tumor necrotic factor TNF $\alpha$ (Puellmann, et al.,2006, Alcaraz-Quiles, et al.,2018). Additional, loss of bronchial epithelium, loss of cilia, and squamous metaplasia and acute fibrinous with organizing pneumonia in later stages causing lung damage (Jin, et al., 2006, Bradley\& Bryan, 2019, De Soto, et al.,2020).

\section{Effect of Covid-19 on CNS:}

There are many nervous manifestations that appeared in Corona virus19 patients such as fever, seizures, stroke, hyposmia and encephalitis (Carod-Artal, 2020). According to (Mao, et al.,2020), the pathogenesis of the invasion of theCovid-19 virus to the CNS is similar to SARS and MERS virus. The covid-19 virus may enter the CNS through the hematogenous or retrograde neuronal route. Multiple cytokine expression could induce immune impairment in the brain in the examination of a large number of children with the acute encephalitis-like syndrome and respiratory tract Corona infection ( $\mathrm{Li}$, et al.,2016). The effect of Covid-19 on the respiratory center worsens the ARDS (Moriguchi, et al.,2020).

\section{Pathological Lesions:}

There are avery small number of pathologic studies have been directed based on autopsies or biopsies. This could be due to the lack of autopsies and biopsies include unexpectedness of the outbreak and high rate of transmission, which makes invasive diagnostic procedures less of a clinical priority.

\section{Lung and Other Organs:}

The lung is the most affected organ in the Covid-19 virus patient causing acute respiratory distress syndrome (ARDS). Histopathological examination of sections away from the Abundant alveolar macrophages was seen in some areas along with type II pneumocystis hyperplasia (Tian, et al.,2020). While Luo et al. (2020) confirmed the same results of covid-19 virus infection,

No obvious intranuclear or intracytoplasmic viral inclusions were identified in another study on the patient 50 years -old man who suffered from fever, chills, cough, fatigue and shortness of breath on Jan 21, 2020. The authors described the histological examination on lung biopsy as bilateral diffuse alveolar damage with cellular fibromyxoid exudates. The right lung showed marked desquamation of pneumocytes and hyaline membrane formation, demonstrating acute respiratory distress syndrome. The left lung tissue showed pulmonary edema with hyaline membrane formation, indicative of early-phase ARDS. Interstitialmononuclear inflammatory infiltrated by lymphocytes and multinucleated syncytial cells were seen in both lungs. Multinucleated syncytial cells with atypical enlarged pneumocytes characterized by large nuclei, amphophilic granularcytoplasm, and prominent nucleoli were identified in theintra-alveolar spaces, showing viral cytopathic-like changes (Xu, et al., 2020).

Tian et al. (2020) described the pathological lesions in the lung in four patients ages ranged from 59 to 81, including 
three males and one female who died of Covid-19 pneumonia.

Diffuse alveolar damage (DAD) in the lung showed hyaline membrane formation and vascular congestion. Advanced changes have appeared in case 4 include remnants of hyaline membranes in some airspace, large areas of intra-alveolar hemorrhages and intraalveolar fibrin clusters infiltrated with mononuclear inflammatory cells and stromal cells. Hyperplasia of type II pneumocyte caused interstitial thickening associated with fibrinoid necrosis of the small vessels. There was also assign of consolidation by abundant intra-alveolar neutrophilic infiltration accompanied with bronchopneumonia due to bacterial infection in the same case.

The liver sections of the patient with COVID19 showed moderate microvascular steatosis and mild lobular and portal activity (Xu, et al., 2020). Tian et al. (2020) noticed mild sinusoidal dilatation, nuclear glycogen accumulation in hepatocytes, focal macrovesicular steatosis, and dense atypical small lymphocytes in portal tracts were seen.

The pathological examination was performed in heart tissue in two cases suffered from covid -19 pneumonia exhibited focal irregular areas in the myocardium with darkened cytoplasm. These changes were not sufficient for interpretation as acute myocardial injury. There were various degrees of focal edema, interstitial fibrosis, and myocardial hypertrophy (Tianet al. 2020).

\section{Natural Extracts (Treatment and Prevention by Invertebrates and Herbs):}

Antiviral agents extracted from natural herbal and invertebrate sources have been used from ancient times for the prevention and treatment of several viral infections including respiratory viral infections. These extracts can help the immune system to stimulate inflammation modulation factors for the management of these viral infections. This effect is based on changing lifestyle habits and modifying dietary intake together with the prophylactic interventions for enhancing the immune system as well as symptomatic treatments. Management of COVID-19 is believed to be based on two strategies; immunity enhancement to control viral replication or virulence and relieving associated symptoms. The common radish Raphanus sativus is an economically important vegetable for the treatment of liver and respiratory diseases in traditional medicine (Abd El-Aziza and ElShehabyb, 2019).

\subsection{Invertebrate's Extracts:}

Natural products have been used widely in folk medicine for various purposes since ancient times. It is estimated that more than $70 \%$ of all existing pharmaceutical products are focused on natural compounds (Wangchuk, 2018, Abd Ellah NH, Abd ElAziz, et al.,2019). The use of invertebrates along with their natural derived products as medicines is one of the features of Traditional Chinese Medicine (TCM). Such materials are a major source of new chemicals with possible therapeutic effects. Much research has been published on the bioactivity and use of invertebrates and their active constituents in TCMs (Liu, et al., 2012). Many TCMs have used Earthworm extracts to treat various diseases, such as decubital necrosis, osteomyelitis, and ecthyma. Earthworms are invertebrate's protective of themselves. The natural habitats of earthworms suggest that the earthworm itself contains strong antimicrobial molecules or antiviral substances (Liu, et al.,2012). Marine invertebrates are one of the largest classes of species. To date, we have discovered a variety of medicinal benefits and many marine natural products (MNPs) from marine invertebrates. Seafood diet from edible marine invertebrates such as mollusks and crustaceans has been related to various medicinal advantages for improving human health Invertebrate-isolated MNPs have shown a wide variety of therapeutic properties including antimicrobial, antioxidant, antihypertensive, anticoagulant, anticancer, anti-inflammatory, wound healing, immune modulator, and other medicinal effects.

Marine invertebrates are thus rich sources of chemical diversity and health benefits for 
emerging candidates for medications, cosmetics, nutritional suppleness (De Zoysa, ,2012). Viruses demonstrate a rapid ability to manipulate and kill host cells, often aided by virus-coded peptides that inhibit host cell immune response. Although many compounds have been identified as inhibiting various viral infections and the progression of the disease, the development of more effective agents is urgently needed. In addition, very few viral vaccines are available, and not all are effective, in comparison to the great variety of diseases caused by viruses. Thus, new antiviral drugs, including those derived from venomous species, obtained from natural products have prospected. Venoms (spider \& scorpion) are complex mixtures of hundreds of molecules, mainly peptides, which pose a broad range of biological activities and have evolved to putatively target biochemical machinery of various pathogens or host cellular structures. Additionally, non-venomous compounds like certain invertebrate organism body fluids exhibit antiviral activity, thereby strengthening them as valuable tools to develop new therapeutic drugs (De Zoysa, ,2012).

\section{$>$ Venomous Species}

(Spider, Scorpion and Insects) and Their Possible Effect on COVID-19:

Spider, scorpion and insects are bellowing to Arthropods which form a complex and largest phylum of Invertebrate. They represent more than 80 percent of all known animal species (Abd El-Aziza and El Shehabyb, 2019, Abd El-Aziza, 2018).

Propolis is a bee(insects)product that has ma ny pharmacological properties and is comm onlyused in folk medicine (Yildirim, et al.,2016):

Numerous studies have recorded that propolis has many pharmacological and bio logical properties, such as antiinflammatory, antibacterial, antifungal, antioxidant, antica ncer, and antiviral effects (Oksuz, et al.,2005, Duran, et al.,2006, Duran, et al.,2011, Salim, etal.,2015, Mendonca, et al.,2015, Nina, et al. ,2015). Spider and scorpion venoms have a number of chemical compounds in them, neurotoxic proteins, salts, acidic proteins, and organic compounds (Abd El-Aziza, et al.,2019). In the 1990s antimicrobial peptides (AMPs) were first discovered from these bacteria. As of May 2015, the Antimicrobial Peptide Database (http:/aps.unmc.edu/AP) contained 42 spiders and 63 scorpion AMPs. These peptides have widespread or narrow-scale action against bacteria, fungi, viruses (Xiuqing and Guangshun ,2016). Hepatitis $\mathrm{C}$ virus (HCV) is a major global health issue, natural antimicrobial peptides (AMPs) have recently gained more attention as biological compounds and can be a good basis to produce therapeutic agents, including antiviral agents against a variety of viruses. Specific AMPs were characterized from the venom of various venomous animals including scorpions (Ziebuhr, et al., 2003).

$>$ Natural Products Inhibiting Cov Through 3CL Protease Inhibition: Isatisindigotica,

Houttuyniacordataaq extracts, Herbal extracts (Gentianascabra ,Dioscoreabatatas, Cassia tora, Taxillus, Curcumin and the 3C-Like Proteinase of an Invertebrate (Ziebuhr,et al., 2003).

* Curcumin: is an oil-soluble substance, with a bright orange-yellow color isolated from the turmeric ground rhizome of Curcuma longa Linn., which has been known as an antioxidant agent (Anand, et al.,2007). The mechanisms of antioxidant and scavenging potential of curcumin in treating lesions of the respiratory system, nervous system and parenchymatous organs have been reviewed by many investigators [Trujillo, et al.,2013).

Several studies demonstrated the neuroprotective effect of curcumin (Kuo, etal.,2011and Manogaran, et al.,2015) which recorded the effect of curcumin on hippocampus after subarachnoid hemorrhage. Douichene et al., (2012) studied the effect of curcumin in arat model for Alzheimer disease by aluminum. Rats were treated with curcumin at a dose of $200 \mathrm{mg} / \mathrm{kg}$ orally for 11 weeks. The results showed moderate neuropathlogical changes, recovered characteristic shape of neurons and decreased 
neuronal loss. Samini et al. (2013) investigated the effect of curcumin on traumatic brain injury in rats. In conclusion, curcumin therapy has a powerful neuroprotective effect.

Licorice Root Extract:Licorice can be used to neutralize the activity of virus proteins. Similar agreements are found in the literature (Cinatl, et al.,2003) that state "licorice root extract is effective against HIV, RSB, herpes viruses and severe acute respiratory syndrome-related coronavirus which causes a serious type of pneumonia". The contents of licorice are glycyrrhizin, glycyrrhetic acid, liquiritin and isoliquiritinthatcan control the spreading of virus activity (Cinatl, et al.,2003).

Indian Medicinal Plants and Their Possible Effect on COVID-19: Indian herbs have been used as a treatment and preventive strategy for many diseases, including respiratory viral infections. The benefit of using such herbs in viral respiratory infections is to help immune-stimulating and inflammation-modulating effects of the immune system (Nourazarian, 2015). A study has shown anti-mouse coronaviral activity (a surrogate of SARS-CoV) by the plants Indigoferatinctoria (AO), Cassiaalata Abutilon Indicum Vitextrifolia, Gymnemasylvestre, Clitoriaternatea, Leucasaspera, Sphaeranthusindicus, Clerodendruminerme Gaertn, Pergulariadaemi and Evolvulusalsinoides (Vimalanathan, et al.,2009).

Vitextrifolia

and

Sphaeranthusindicus are found to reduce inflammatory cytokines using the NF-kB pathway, a pathway that has been implicated in respiratory distress in SARS-CoV (Alam, et al.,2002). Clitoriaternatea has been identified as a metalloproteinase inhibitor, ADAM17, a metalloproteinase that is involved in ACE shredding can be targeted using this plant, as ACE-2 shredding has been associated with an increased formation of viruses (Maity, et al.,2012). The plants Glycyrrhizaglabra (Nourazarian, 2015) and Allium sativumcan be used to target the viral replication of SARS-CoV, arising as promising candidates against SARS-CoV-2. ClerodendruminermeGaertn, isa herb has been found to have the potential to inactivate the viral ribosome, this can be further investigated for its utility as a drug targeting SARS-CoV-2 protein translation (Olivieri, et al.,1996).

StrobilanthesCusia blocked the viral RNA genome synthesis and stimulate papainlike protease activity targeting the $\mathrm{HCoV}$ (Tsai, et al.,2020). Hyoscyamusniger, Justiciaadhatoda and Verbascumthapsus reduced infections caused by influenza viruses. The molecular mechanism by which these plants target the influenza virus can be studied to understand if they attack any molecules overlapping between SARS-CoV2 and the Influenza viruses. Hyoscyamusniger was found to be a bronchodilator and had inhibitory effects on $\mathrm{Ca}^{2+}$ channel (Gilani, et al.,2008). This could be used to target the orf3a $\mathrm{Ca}^{2+}$ channels that trigger various downstream pathways upon viral infection.

\subsection{Natural Plant Extracts of ACE Inhibitors:}

Most importantly, various medicinal plants have shown inhibitory effects against $\mathrm{ACE}$, and these include Coriandrumsativum (Hussain, et al.,2018).

* Boerhaaviadiffusa, Cynarascolymus, Cosciniumfenestratum, Punicagranatum Cassia occidentalis and Embeliaribes. Among them, Punicagranatum showed a competitive mode of action while the rest were non-specific inhibitors (Khan, and Kumar,2019).

* Andrographispaniculata (kalmegh) is one of the tropical species in the Acanthaceae family, present in South Asia has a strong treating capacity of viral respiratory infections in Ayurvedic and other medicinal systems (Yarnell, 2018).

* Andrographispaniculata has been noted to suppress increased NOD-like receptor protein 3 (NLRP3), caspase-1, and interleukin-1 $\beta$ molecules which are extensively involved in the pathogenesis of SARS-COV and likely SARS-CoV-2 as well (Liu, et al.,2020, Liu, et al., 2020). 
* Salacia oblonga (He, et al.,2011) another plant from Tamil Nadu has also displayed suppressive effects on angiotensin II, AT1 signal, which was related to lung damage. Many plants have also shown inhibitory actions towards HIV proteases, these plants can be promising drugs for COVID-19.

* Eugenia jambolana (Otake, et al.,1995): Euphorbia granulate.

* Solanumnigrum (Yu, 2004), Vitexnegundo have been known to target the reverse transcriptase activity of HIV and can be studied for activity against SARS-CoV-2 as well.

* Sambucusebulus (Ganjhu, et al.,2015) has been known to inhibit the activity of enveloped viruses and can also be used to target this virus. These medicinal plants can be used to ameliorate the symptoms of COVID-19. Though many medicinal plants have been identified, a lot of research must be carried out for the development of drug-specific to SARSCoV-2.

- Natural Extracts Acting as Prophylactic Therapy:Many plant extracts have shown promising effects in this concept. Many Indian plants available as aqueous extracts and tablets have been reported to be effective as a preventive, prophylactic treatment having antioxidant, anti-allergic, anti-influenza activity and act as immune modulators making them effective against SARS-COV-2 (Vellingiri, et al., 2020). Some of these plants act as a metalloproteinase inhibitor that prevents ACE shredding and so shrivel viral replication (Maity, et al.,2012). The same effect was found with Coriandrums ativum (Hussain, et al.,2018). Glycyrrhiza glabra targets virus replication by changing membrane fluidity. Some herbs acting by inactivating viral ribosomes so blocking viral protein translation while others inhibit the synthesis of the viral RNA genome (Tsai, etal.,2020). Another study reported that a Chinese herb, known as cinanserin which is a serotonin receptor antagonist, has the ability to block the enzyme 3 chymotrypsin-like proteases $\left(3 \mathrm{CL}^{\text {pro }}\right)$ thus inhibiting coronavirus replication (Chen, et al.,2005, Panche, et al, 2016). The same $3 C^{\text {proinhibitory effect was }}$ also found with many antioxidant flavonoids such as herbacetine, isobavachalcone, helichrysetin and quercetin (Jo, et al.,2019, Jo, et al.,2020).

\section{- Natural Extracts Acting as} Symptomatic Therapy: In the same way, many Indian plants also act against fever and respiratory distress reducing lung inflammation caused by the COVID-19 virus. A study revealed anti-cytokine activity using NF-KB pathway that is implicated in the respiratory side effects caused by SARSCOV. They are prepared as tablets and oil/aqueous extracts (Vellingiri, et al., 2020). One of the tropical medicinal herbs, Andrographis paniculata, was reported to suppress many modulatory factors such as caspase-1, and interleukin-1 $\beta$ involved in SARS-COV and consequently SARS-CoV-2 pathogenesis (Liu, et al.,2020, Liu, et al., 2020). In a recent study, there were about 13 herbal formulae prepared from traditional Chinese medicine that is recommended to be used in the treatment of several respiratory tract infections including COVID-19 especially pediatric infections (Ang, et al.,2020). Most of these herbs are prepared as an oral decoction and some are decoction enema preparations (Ang, et al.,2020). The cases that are studied included mild cases with seasonal epidemic invading the exterior-defense, moderate cases with dampness-heat blocking the lung and severe cases with dampness-heat in the spleen and stomach and heat toxin block the lung (Ang, et al.,2020). According to their analysis, there are three herbs used together named Scutellariae radix, Artemisiae annuae herba, and Belamcandae rhizoma that are effective in relieving heat associated COVID-19 infection (Ang, et al.,2020). Scutellariae radix containing baicalin as the main bioactive compound has antiviral activity against SARS, pneumonia and upper respiratory tract infections (Chen, et al., 2004). Another herbal formula containing Armeniacae Semen and Coicis 
Semenwasused in traditional medicine in the treatment of upper respiratory infection as they both have a nourishing effect on the lungs (Xi and Gong, 2017). It was found that the most frequently used herb is Armeniacae semenas it has an inhibitory effect on $\mathrm{Th}_{2}$ cells thus blocking the airway obstruction and thus may reduce respiratory symptoms caused by viral infections in children (Huang, et al., 2013). Because the severity of COVID-19symptoms in adults is much fiercer than in children, the herb Glycyrrhizae radix was found to be most frequently used as anti-inflammatory and antiviral medicine (Ang, et al.,2020).

\section{Conclusion:}

(COVID-19) the outbreak of coronavirus has caused a global coronavirus disease pandemic in 2019, leading to tens of thousands of infections and thousands of deaths worldwide. Coronaviruses are implicated in illnesses of humans, vertebrates and invertebrates. There is currently no effective treatment for COVID-19. It is necessary to determine the basis of its replication, structure and pathogenicity for finding a way to special treatment or prevention. From ancient times antiviral agents extracted from natural herbal and invertebrate sources have been used to prevent and treat a number of viral infections including respiratory viral infections. COVID-19 management is believed to be based on two strategies; enhancement of immunity to control viral replication or virulence and relieve associated symptoms. This review strengthens the use of natural extracts as valuable tools to develop new therapeutic drugs against COVID-19.

\section{REFERENCES}

Abd El-Aziza, F.A. (2018): Morphological Characterization of Arthropod Ectoparasites by Scanning Electron Microscopy. Egyptian Academic Journal of Biological Sciences, B. Zoology.10 (1): 93- 104.

Abd El-Aziza, F.A. and El Shehabyb ,D.M.,(2019): Effect of Arthropods on the Decomposition of Rat Carrions in an Aerated Environment in Spring Season in Assiut, Egypt. Egyptian Academic Journal of Biological Sciences, B. Zoology.11(1): 1- 12.

Abd El-Aziza, F.A. El Shehabyb, D.M. Elghazally c, S.A., Hetta,H.F.(2019): Toxicological and epidemiological studies of scorpion sting cases and morphological characterization of scorpions (Leiurus quinquestriatus and Androctonus crassicauda) in Luxor, Egypt. Toxicology Reports, 6: 329-335.

Abd Ellah NH, Abd El-Aziz F.A., Abouelmagd S.A., Abd El-Hamid B.N., Hetta H.F. (2019)." Spidroin in carbopol-based gel promotes wound healing in earthworm's skin model. Drug Development Research;1-11. https://doi.org/10. 1002/ddr.21583

Alam, G., Wahyuono, S., Ganjar, I.G., Hakim, L. H. Timmerman, R. (2002): Verpoorte Tracheospasmolytic vitexicarpin isolated from Vitextrifolia. Planta Medica, 68 pp. 1047-1049, 10.1055/s-2002-35650

Alcaraz-Quiles, J., Casulleras, M., Oettl, K., Titos, E., Flores-Costa, R., DuranGüell, M.\&Clària, J. (2018). Oxidized albumin triggers a cytokine storm in leukocytes through p38 Mitogen-Activated protein kinase: role in systemic inflammation in decompensated cirrhosis. Hepatology, 68(5), 1937-1952.

Anand, P., Kunnumakkara, A. B., Newman, R. A., \&Aggarwal, B. B. (2007). Bioavailability of curcumin: problems and promises. Molecular pharmaceutics, 4(6), 807-818

Ang,L., Hye W. Lee, A. K., Ju A. L., Junhua Z., Myeong S.L. (2020): Herbal medicine for treatment of children diagnosed with COVID19: A review of guidelines, Complementary Therapies in Clinical Practice, Vol.39, ,101174, ISSN 1744-3881. https://doi.org/ 10.1016/j.ctcp.2020.101174. 
Beltrán-Corbellini, Á.; Chico-García, J.L.; Martínez-Poles, J.; Rodríguez-Jorge, F.; Alonso-Cánovas, A. (2020). Replyto letter: Acute-onset smell and taste disorders in the context of Covid-19: A pilot multicenter PCRbasedcase-control study. European Journal of Neurology, 27(9): 17381741.doi: 10.1111/ene. 14273.

Bernard Stoecklin S, Rolland P, Silue Y et al. (2020): First cases of coronavirus disease 2019 (COVID-19) in France: surveillance, investigations and control measures, Eurosurveillance, 2020; 25: 2000094.

Bloom, P.P.; Meyerowitz, E.A.; Reinus, Z.; Daidone, M.; Gustafson, J.; Kim, A.Y.; Schaefer, E.; Chung, R.T. (2020): Liver Biochemistries in Hospitalized Patients With COVID19. Hepatology, 73(3), 890900. https://doi.org/10.1002/hep.313 26.

Bradley, B. T., \& Bryan, A. (2019). Emerging Respiratory Infections: The infectious disease pathology of SARS, MERS, pandemic influenza, and Legionella.In Seminars in diagnostic pathology. WB Saunders.

Carod-Artal, F. J. (2020). Neurological complications of coronavirus and COVID-19. Revista Neurologia, 70(9), 311-322.

Carod-Artal, F.J. (2020): Neurological complications of coronavirus and COVID-19. Revista de Neurología, 70, 311-322.

Chen $\mathrm{Yu}$, Qianyun Liu and DeyinGuo. (2020); Emerging coronaviruses: Genome structure, replication, and pathogenesis. Journal of Medical Virology, 1-6.

Chen, F. K.H. Chan, Y. Jiang, R.Y.T. Kao, H.T. Lu, K.W. Fan, V.C.C. Cheng, W.H. Tsui, W.I.F.N. Hung, T.S.W. Lee, Y. Guan, J.S.M. Peiris, K.Y. Yuen. (2004): In vitro susceptibility of 10 clinical isolates of SARS coronavirus to selected antiviral compounds, Journal of Clinical
Virology,31 (1): 69-75.

Chen, L., Gui,C.,Luo,X.,Yang,Q.,Günther, S., Scandella,E.Drosten, C., Bai. D., He,X., $\quad$ Ludewig,B.,(2005): Cinanserin is an inhibitor of the $3 \mathrm{C}$ likeproteinaseofsevere acute respiratory syndrome coronavirus and strongly reduces virus replication in vitro. Journal of Virology, 79,7095-7103.

Cinatl, J., B. Morgenstern, G. Bauer, P. Chandra, H. Rabenau, and H. W. Doerr (2003). "Glycyrrhizin, an active component of liquorice roots, and replication of SARS-associated coronavirus." The Lancet, 3(2009)61, no. 9374: 2045-2046.

Dalia,D.K., Abdessamad D.A., Noureddine ,B.,(2021): SARS-CoV-2 \& COVID-19. From Virology to Epidemiology: "Epidemiological situation in Algeria and in West Algerian area". Egyptian Academic Journal of Biological Sciences C Physiology and Molecular Biology. 13(1): 41-59.

De Soto, J.; Hakim, S.; Boyd, F. The Pathophysiology of Virulence of the COVID-19 Virus. Preprints, 2020, 2020040077 (doi: 10.20944/ preprints202004. 0077.v1).

De Zoysa, M, (2012): Medicinal Benefits of Marine Invertebrates, Advances in food and nutrition research, 65:15369.

Douichene, S., Djebli, N., Ahmed, M., \&Zerrouki, K. (2012). Neuroprotective effect of curcumin with a fixator of absorption against both aluminium neurotoxicity and Alzheimer's disease (experimental studies in mice). Journal of Alzheimers Disease \& Parkinsonism, 2(107), 2161-0460.

Du, Y.; Tu, L.; Zhu, P.; Mu, M.; Wang, R.; Yang, P.; Wang, X.; Hu, C.; Ping, R.; $\mathrm{Hu}, \mathrm{P}$; et al. (2020): Clinical Features of85 Fatal Cases of COVID-19 from Wuhan: A Retrospective Observational Study. 
SSRN Electronic Journal, 201,13721379.

Duran N, Koc A, Oksuz H, Tamer,C., Akaydin, Y., Kozlu, T.,Celik, M.,(2006):The protective role of topical propolis on experimental keratitis via nitric oxide levels in rabbits. Molecular Cell Biochemistry, 281(1-2):153-61.

Duran N, Muz M, Culha G, Duran, G., Ozer,B., (2011): GC-MS analysis and antileishmanial activities of two Turkish propolis types. Parasitology Research, ;108(1):95-105.

EL-Mahdi,M.,(2020): Sequence Analysis and Variations in the 5' UTR genomic regions of Coronaviruses. Egyptian Academic Journal of Biological Sciences C Physiology and Molecular Biology, Vol 12(2): pp. 201-211.

Ganjhu, R.K.,Mudgal, P.P. H. Maity, D. Dowarha, S. Devadiga, S. Nag, G. Arunkumar(2015): Herbal plants and plant preparations as remedial approach for viral diseases. Virus disease, 26: 225-236.

Gilani, A.H., Khan, A. M. Raoof, M.N. Ghayur, B.S. Siddiqui, W. Vohra, S. Begum Gastrointestinal, (2008): selective airways and urinary bladder relaxant effects of Hyoscyamusniger are mediated through dual blockade of muscarinic receptors and $\mathrm{Ca}^{2+}$ channelsFundam. The Journal of Clinical Pharmacology, 22, pp. 87-99, 10.1111/j.1472-8206.2007. 00561.x

Griffin, D.O.; Jensen, A.; Khan, M.; Chin, J.; Chin, K.; Saad, J.; Parnell, R.; Awwad, C.; Patel, D. (2020): PulmonaryEmbolism and Increased Levels of d-Dimer in Patients with Coronavirus Disease. Emerging Infectious Diseases journal, 26.

Grillet, F.; Behr, J.; Calame, P.; Aubry, S.; Delabrousse, E. (2020): Acute Pulmonary Embolism Associated withCOVID-19 Pneumonia
Detected by Pulmonary $\mathrm{Ct}$ Angiography. Radiology.

He, L., Y. Qi, X. Rong, J. Jiang, Q. Yang, J. Yamahara, M. Murray, Y. Li (2011), The Ayurvedic medicine Salacia oblonga attenuates diabetic renal fibrosis in rats: suppression of angiotensin II/AT1 signaling. Based Complement. Evidence-Based Complementary and Alternative Medicine., p. 12,

Helena J. M., Erica B. and Paul B. (2015); Coronaviruses: An Overview of Their Replication and Pathogenesis. Nature Public Health Emergency Collection, 1282: 1-23.

Holshue ML, DeBolt C, Lindquist $\mathrm{S}$ et al. (2020): First Case of 2019 Novel Coronavirus in the United States. The New England Journal of Medicine; 382: 929- 36.

Hopkins, C.; Surda, P.; Kumar, N. (2020): Presentation of new onset anosmia during the COVID-19 pandemic.Rhinology

Huang, C.; Wang, Y.; Li, X.; Ren, L.; Zhao, J.; Hu, Y.; Zhang, L.; Fan, G.; Xu, J.; Gu, X.; et al. (2020): Clinical featuresof patients infected with 2019 novel coronavirus in Wuhan, China. Lancet, 395, 497-506.

Huang, T. P. Liu, A. Lien, S. Yang, H. Chang, H. Yen, (2013): Characteristics of traditional Chinese medicine use in children with asthma: a nationwide population-based study. Allergy, 68 (12) :1610-1613.

Hughes, C., Nichols, T., Pike, M., Subbe, C., \&Elghenzai, S. (2020). Cerebral Venous Sinus Thrombosis as a Presentation of COVID-19. European journal of case reports in internal medicine, 7(5), 001691. https://doi.org/10.12890/2020_0016 91

Hussain, F., Jahan, N., Rahman, K., Sultana, B., Jamil, S., (2018): Identification of hypotensive biofunctional compounds of Coriandrum sativum and evaluation of their angiotensin- 
converting enzyme (ACE) inhibition potential. Oxidative Medicine and Cellular Longevity, 3, 1-11. https://doi.org/10.1155/2018/46437 36.

Jin, X. H., Ohgami, K., Shiratori, K., Suzuki, Y., Hirano, T., Koyama, Y., \&Ohno, S. (2006). Inhibitory effects of lutein on endotoxin-induced uveitis in Lewis rats. Investigative ophthalmology \& visual science, 47(6), 2562-2568.

Jo S., Kim S., ShinD.H., KimM. -S. (2020): Inhibition of SARS CoV3CLproteaseby flavonoids. Journal of Enzyme Inhibition and Medicinal Chemistry:.35:145-151.

Jo, S. Kim, S. Kim, D.H. Shin, M.S. Kim. (2019): Characteristics of flavonoids as potent MERS-CoV 3C-like protease inhibitors. Chemical Biology \& Drug Design,94:2023-2030.

Kang, Y.; Chen, T.; Mui, D.; Ferrari, V.; Jagasia, D.; Scherrer-Crosbie, M.; Chen, Y.; Han, Y. (2020): Cardiovascular manifestations and treatment considerations in covid19. Heart.

Khan, M.Y., Kumar,V. (2019): Mechanism \& inhibition kinetics of bioassayguided fractions of Indian medicinal plants and foods as ACE inhibitors. Journal of Traditional and Complementary Medicine, 9, pp. 7384 ,

Kuo, C. P., Lu, C. H., Wen, L. L., Cherng, C. H., Wong, C. S., Borel, C. O., \& Wu, C. T. (2011). Neuroprotective effect of curcumin in an experimental rat model of subarachnoid hemorrhage. Anesthesiology: The Journal of the American Society of Anesthesiologists, 115(6), 12291238.

Lei, S.; Jiang, F.; Su, W.; Chen, C.; Chen, J.; Mei, W.; Zhan, L.Y.; Jia, Y.; Zhang, L.; Liu, D., Zhong-Yuan X., Zhengyuan X. (2020): Clinical characteristics and outcomes of patients undergoing surgeries during the incubation period of COVID19infection. Clinical Medicine, 21, 100331.

Letko, M., Marzi, A., \& Munster, V. (2020). Functional assessment of cell entry and receptor usage for SARS-CoV-2 and other lineage B betacoronaviruses. Nature microbiology, 5(4), 562-569.

Li, Y., Li, H., Fan, R., Wen, B., Zhang, J., Cao, X., \&Lv, X. (2016). Coronavirus infections in the central nervous system and respiratory tract show distinct features in hospitalized children. Intervirology, 59(3), 163169.

Liu J, Liao X, Qian S et al. (2020): Community transmission of severe acute respiratory syndrome coronavirus 2, Shenzhen, China, 2020. Emerging Infectious Diseases journal, doi.org/10.3201/eid2606. 200239.

Liu, Y.T., Chen, H.W., Lii, C.K., Jhuang, J.H., Huang, C.S., Li, M.L., Yao, H.T., (2020): Aditerpenoid,14deoxy-11, 12didehydroandrographolide, in Andrographis paniculata reduces steatohepatitis and liver injury in mice fed a high-fat and highcholesterol diet. Nutrients, 12, 523.https://doi.org/10.3390/nu120 20523.

Liu, Z., Wang, J. Zhang, Baofeng Y., Bo Niu (2012): An extract from the earthworm Eisenia fetida nonspecifically inhibits the activity of influenza and adenoviruses. Journal of Traditional Chinese Medicine. 15; 32(4): 657-663.

Liu, Z., Xiao, X., Wei, X., Li, J., Yang, J., Tan, H., Zhu, J., Zhang, Q., Wu, J., Liu,L.,(2020): Com- position and divergence of coronavirus spike proteins and host ACE2 receptors predict potential intermediate hosts of SARS-CoV-2. Journal of 
Medical Virology, https://doi.org/10.1002/jmv.25726.

Luo, W., Yu, H., Gou, J., Li, X., Sun, Y., Li, J., \& Liu, L. (2020). Clinical pathology of critical patient with novel coronavirus pneumonia (COVID-19). Pathology \& Pathobiology, 2020020407.

Mahase E. (2020); Covid 19: WHO declares pandemic because of "alarming levels" of spread, severity, and inaction. BMJ, 368: m1036.

Maity, N., Nema, N.K., Sarkar, B.K., Mukherjee, P.K., (2012):

Standardized Clitoriaternatea leaf extract as hyaluronidase, elastase and matrix-metalloproteinase-1 inhibitor. Indian Journal of Pharmacology, 44, 584. https://doi.org/10.4103/0253-7613. 100381.

Manogaran, E., Ramanathan, M., \&RamaRao, T. (2015). Effect of Curcumin against Cholesterol Induced Neuroinflammation in InVitro and In-Vivo Models. Journal of Pharmaceutical Sciences and Research, 7(4), 189.

Mao, L., Wang, M., Chen, S., He, Q., Chang, J., Hong, C., \& Li, Y. (2020). Neurological manifestations of hospitalized patients with COVID19 in Wuhan, China: a retrospective case series study

Mendonca IC, Porto IC, do Nascimento TG, et al. (2015); Brazilian red propolis: phytochemical screening, antioxidant activity and effect against cancer cells. BMC Complementary and Alternative Medicine, 15(1):357-69.

Moriguchi, T., Harii, N., Goto, J., Harada, D., Sugawara, H., Takamino, J., Nakao, A. Takeda M., Haro ,H., Inoue, O., Suzuki-Inoue , K. Kubokawa ,K., Shinji Ogihara , Tomoyuki S., Hiroyuki K., Hiroyuki K., Masami I. Hiroshi O., Tatsuya S., Yu S., Nobuyuki E., Hiroshi I., Shiomi F., Tomoko Y., Shinji S., (2020). A first
Case of Meningitis/Encephalitis associated with SARS-Coronavirus2. International Journal of Infectious Diseases, ;94:55-58. doi: 10.1016/j.ijid.2020.03.062.

Nina N, Quispe C, Jimenez-Aspee F, et al. (2015): Antibacterial activity, antioxidant effect and chemical composition of propolis from the region del Maule, Central Chile. Molecules, ;20(10):1814467.

Nourazarian A.J., (2015): Effect of root extracts of medicinal herb Glycyrrhizaglabra on HSP90 gene expression and apoptosis in the HT29 colon cancer cell line. Asian Pacific Journal of Cancer Prevention.2011 pp. 1-16, 10.7314/ APJCP.2015.16.18.8563

Oksuz H, Duran N, Tamer C, et al. (2005): Effect of propolis in the treatment of experimental Staphylococcus aureus keratitis in rabbits. Ophthalmic Research,37(6):328-34.

Olivieri, F., Prasad, V.P. Valbonesi, S. Srivastava, P. Ghosal-Chowdhury, L. Barbieri, A. Bolognesi, F. Stirpe(1996), A systemic antiviral resistance-inducing protein isolated from Clerodendruminerme Gaertn. Is a polynucleotide: adenosine glycosidase (ribosome-inactivating protein). FEBS Letters,396 :132134.

Ong SW, Tan YK, Chia PY, Lee TH, Ng OT, Wong MS, et al. (2020): Air, surface environmental, and personal protective equipment contamination by severe acute respiratory syndrome coronavirus 2 (SARSCoV-2) from a symptomatic patient. JAMA.

Otake, T. H. Mori, M. Morimoto, N. Ueba, S. Sutardjo, I.T. Kusumoto, M. Hattori, T. Namba(1995):Screening of Indonesian plant extracts for antihuman immunodeficiency virustype 1 (HIV-1) activity. Phytotherapy Research, 9: 6-10 
Panche,

A.,

Diwan,

A., Chandra,S.,(2016):Flavonoids:anov erview, Journal of Nutritional Science,5(2016) :e47. https://doi.org/10.1017/jns.2016.41.

Pradesh U., Upadhayay P.D.D, Vigyan P.C. (2014): Coronavirus infection in equines: A review. Asian Journal of Animal and Veterinary Advances.;9(3):164-76.

Puellmann, K., Beham, A. W., \& Kaminski, W. E. (2006). Cytokine storm and an anti-CD28 monoclonal antibody. The New England journal of medicine, 355(24), 2592-3.

Punithavathi, D., Venkatesan, N., \&Babu, M. (2003). Protective effects of curcumin against amiodaroneinduced pulmonary fibrosis in rats. British journal of pharmacology, 139(7), 1342-1350.

Remuzzi A, RemuzziG.(2020):COVID-19 and Italy: what next? The Lancet; 395: 1225-8.

Salim EI, Abd El-Magid AD, Farara KM, et al. (2015): Antitumoral and antioxidant potential of Egyptian propolis against the PC3 prostate cancer cell line. Asian Pacific Journal of Cancer Prevention. ;16(17):7641-51.

Samini, F., Samarghandian, S., Borji, A., \&Mohammadi, G. (2013). Curcumin pretreatment attenuates brain lesion size and improves neurological function following traumatic brain injury in the rat. Pharmacology Biochemistry and Behavior, 110, 238-244.

Seah, I.; Agarwal, R. (2020): Can the Coronavirus Disease 2019 (COVID19) Affect the Eyes? A Review ofCoronaviruses and Ocular Implications in Humans and Animals. Ocular Immunology and Inflammation, 28, 391-395.

South, A.M.; Diz, D.I.; Chappell, M.C. (2020): COVID-19, ACE2, and the cardiovascular consequences. The American Journal of Physiology-
Heart and Circulatory Physiology, 318, H1084-H1090.

Tian, S., Hu, W., Niu, L., Liu, H., Xu, H., \& Xiao, S. Y. (2020). Pulmonary pathology of early phase 2019 novel coronavirus

(COVID-19) pneumonia in two patients with lung cancer. Journal of Thoracic Oncology, 15(5):700-704. doi: 10.1016/j.jtho.2020.02.010.

Trujillo, J., Chirino, Y. I., Molina-Jijón, E., Andérica-Romero, A. C., Tapia, E., \&Pedraza-Chaverrí, J. (2013). Renoprotective effect of the antioxidant curcumin: Recent findings. Redox Biology Journal, 1(1), 448-456.

Tsai, Y.C., Lee, C.L., Yen, H.R., Chang, Y.S., Lin, Y.P., Huang, S.H., Lin, C.W., (2020): Antiviral action of Tryptanthrin isolated from Strobilanthescusia leaf against human coronavirus NL63. Biomolecules, 10, 366. https://doi. org/10.3390/biom10030366.

Van Regenmortel MHV, Fauquet CM, Bishop DHL, Carstens EB, Estes MK, Lemon SM, et al. Coronaviridae. In: MHV $\mathrm{v}$ R, Fauquet CM, DHL B, Carstens EB, Estes MK, Lemon SM, et al., editors. (2000): Virus taxonomy: Classification and nomenclature of viruses Seventh report of the International Committee on Taxonomy of Viruses. San Diego: Academic Press; p. 835-49. ISBN 0123702003.

Vellingiri,B.Kaavya J., Mahalaxmi I., Arul N., Vivekanandhan G., Bupesh G., Singaravelu G., Anila V., Dhivya V., Harsha G., Kamarajan R., Pattanathu K.S.M. Rahman, Ssang-Goo Cho, Nachimuthu S. K., Mohana D. S., (2020) : COVID-19: A promising cure for the global panic. Science of the Total Environment Journal,V(725), 138277, ISSN 0048-9697, https://doi.org/10.1016/ j.scitotenv.2020.138277. 
Vetter, P., Diem L, Vu, Arnaud G.L., Manuel Sc., Laurent $\mathrm{K}$. and Frederique J.(2020): Clinical features of covid19. BMJ;369:m1470

Vimalanathan, S. Ignacimuthu, J. Hudson (2009): Medicinal plants of Tamil Nadu (southern India) are a rich source of antiviral activities. Pharmaceutical Biology, 47, pp. 422-429, $10.1080 /$ 13880200902800196

Wangchuk, P. (2018). Therapeutic Applications of Natural Products in Herbal Medicines, Biodiscovery Programs, and Biomedicine. Journal of Biologically Active Products from Nature, 8(1), 1-20. doi:10.1080/ 22311866.2018.1426495

World Health Organization (2020). Report of the WHO-China Joint Mission on Coronavirus Disease 2019 (COVID19) 16-24 February [Internet]. Geneva: World Health Organization; 2020 Available from: https:// www.who.int/docs/default- source/ corona viruse/who-china-jointmission-on-covid-19-final-report.

World Health Organization. (2020): WHO director-general's opening remarks at the media briefing on covid-19.11 March. https://www.who.int/dg/ speeches/detail/who-directorgeneral-s-opening-remarks-at-themedia-briefing-on-covid-19---11march-2020

World Health Organization; (2014): Infection prevention and control of epidemicand pandemic-prone acute respiratory infections in health care. Geneva: World Health Organization.

$\mathrm{Wu}$ Z. and McGoogan JM. (2020): Characteristics of and Important Lessons from the Coronavirus Disease 2019 (COVID-19) Outbreak in China: Summary of a Report of 72314 Cases from the Chinese Center for Disease Control and Prevention. JAMA.

Wu, J.; Liu, J.; Zhao, X.; Liu, C.; Wang, W.; Wang, D.; Xu, W.; Zhang, C.; Yu, J.;
Jiang, B.; Cao, H., Li, L., (2020): Clinical Characteristics of Imported Cases of Coronavirus Disease 2019 (COVID-19) in Jiangsu Province: A Multicenter Descriptive Study. Clinical Infectious Diseases, :28;71(15):706-712. doi: 10.1093/ cid/ciaa199.

Xi, S.Y., Gong, Y.W. (2017): Essentials of Chinese Materia Medica and Medical Formulas: New Century Traditional Chinese Medicine, first ed., Academic Press,

Xiao, F.; Tang, M.; Zheng, X.; Liu, Y.; Li, X.; Shan, H. (2020): Evidence for Gastrointestinal Infection of SARSCoV-2. Gastroenterology, 158, 1831-1833.

Xiuqing W. and Guangshun W.(2016): Insights into Antimicrobial Peptides from Spiders and Scorpions. Protein and Peptide Letters, 23(999) 10.2174/0929866523666160511151 320

Xu, Z., Shi, L., Wang, Y., Zhang, J., Huang, L., Zhang, C., ...\& Tai, Y. (2020). Pathological findings of COVID-19 associated with acute respiratory distress syndrome. The Lancet respiratory medicine, 8(4), 420-422.

Yarnell,E. (2018): Herbs for viral respiratory infections. Alternative and Complementary Therapies, 24: 3543,

Yildirim, A., GulayG.Duran, N. Duran, Kemal J.,Behiye S. Bolgul (2016): Antiviral Activity of Hatay Propolis Against Replication of Herpes Simplex Virus Type 1 and Type 2. Medical Science Monitor, 22: 422430.

Yin, R.; Feng, W.; Wang, T.; Chen, G.; Wu, T.; Chen, D.; Lv, T.; Xiang, D. (2019): Concomitant neurological symptoms observed in a patient diagnosed with coronavirus disease. Journal of Medical Virology, 2020.

$\mathrm{Yu}, \quad \mathrm{Y}$. B. (2004): The extracts of Solanumnigrum L. for inhibitory effects on HIV-1 and its essential 
enzymes. Korean Journal of Oriental Medicine, 10 pp. 119-126.

Zhao L, Jha BK, Wu A, , Elliott,R., Ziebuhr, J.,Gorbalenya, A.E.,Robert H., .,Silverman, Weiss,S.R., (2012): Antagonism of the interferoninduced OAS-RNase L pathway by murine coronavirus ns2 protein is required for virus replication and liver pathology. Cell Host Microbe, 11: 607-616.

Zhou P,Yang XL, Wang XG, , Ben H.u., ZhangL., Wei Z., Hao-Rui Si , Yan Z., Bei L., Chao-Lin H., Hui-Dong C., Jing C., Yun L., Hua G., Ren-Di J., Mei-Qin L., Ying C., Xu-Rui S.,
Xi W., Xiao-Shuang Z., Kai Z., Quan-Jiao C., Fei D., Lin-Lin L., Bing Y., Fa-Xian Z., Yan-Yi W., Geng-Fu X., Zheng-Li S., (2020): A pneumonia outbreak associated with a new coronavirus of probable bat origin. Nature; 579:270-3.

Ziebuhr,J., Sonja B., Jeff

A. Cowley, Alexander

E. Gorbalenya.,(2003): The 3C-Like Proteinase of an Invertebrate Nidovirus Links Coronavirus and Potyvirus Homologs. Journal of Virology, Jan.Vol.77.no.2, p. 14151426. 